\title{
Fantastic Cheats- Where and how to find them? How to tackle them?
}

\section{Dr. Ashish D Borgaonkar, New Jersey Institute of Technology}

Dr. Ashish Borgaonkar works as Asst. Professor of Engineering Education at the New Jersey Institute of Technology's Newark College of Engineering located in Newark, New Jersey. He has developed and taught several engineering courses primarily in first-year engineering, civil and environmental engineering, and general engineering. He has won multiple awards for excellence in instruction. He also has worked on several research projects, programs, and initiatives to help students bridge the gap between high school and college as well as preparing students for the rigors of mathematics. His research interests include engineering education, integration of novel technologies into engineering classroom, excellence in instruction, water, and wastewater treatment, civil engineering infrastructure, and transportation engineering.

\section{Dr. Christina Marie Zambrano-Varghese, Rutgers University-Newark}

Christina Zambrano-Varghese is an Assistant Teaching Professor of Psychology at Rutgers UniversityNewark, where she teaches a wide variety of courses ranging from introductory to upper-level research methods. She has conducted research on plagiarism prevention strategies and has transformed her courses to achieve academic honesty among all students. She was the 2018-2019 Chancellor's Scholar-in-Residence, responsible for organizing faculty development workshops and developing protocols to enhance teaching across disciplines, focusing in particular on the teaching of professional writing across disciplines and prevention of academic dishonesty.

\section{Dr. Jaskirat Sodhi, New Jersey Institute of Technology}

Dr. Jaskirat Sodhi is interested in first-year engineering curriculum design and recruitment, retention and success of engineering students. He is the coordinator of ENGR101, an application-oriented course for engineering students placed in pre-calculus courses. He has also developed and co-teaches the Fundamentals of Engineering Design course that includes a wide spectra of activities to teach general engineering students the basics of engineering design using a hands-on approach which is also engaging and fun. He is an Institute for Teaching Excellence Fellow and the recipient of NJIT's 2018 Saul K. Fenster Innovation in Engineering Education Award.

\section{Dr. Swapnil Moon}




\section{Fantastic Cheats: Where to Find Them? How to Tackle Them?}

\section{Background - why do students cheat?}

This is a full survey paper of literature and practice in dealing with academic integrity violations in higher education. Academic integrity is often an abstract concept, a term that many students are familiar with, but one that may not be completely understood in terms of breadth or importance. Academic integrity violations can range from cheating through premeditation by bringing restricted materials into an exam to glancing at another student's exam [1]. Violations of academic integrity can involve plagiarism, which includes taking the words or ideas of another person and passing them off as one's own [2], or can involve working with other students on an assignment when the expectation was that homework should be completed alone [3]. Although most universities define academic integrity similarly, the ways in which this area of policy and education differ tremendously across institutions [2]. The concept of academic integrity is something that students may have heard of frequently, may even fear violating, but many students fail to integrate the underlying values and purposes of abiding by academic integrity within their own lives. The debate over whether academic dishonesty is on the rise or whether technology has altered the way that violations appear is ongoing; however, what is imperative is that engineering educators begin to work to integrate this crucial aspect of one's education into the objectives of their courses. Students need to learn that academic honesty is a critical part of their educational endeavors and that their future work as an engineer is dependent upon the professional ethics that they must uphold.

There are many types of academic integrity violations, ranging from minor to more severe. One current type of violation is contract cheating, first coined by Lancaster and Clarke in 2006, which involves paying a third-party to complete an assignment instead of the student enrolled in the class [4]. Some researchers have even discovered "ghost students," in which a fee is paid for another person or company to enroll in an online course for an entire semester on behalf of someone else [5]. Even though contract cheating and ghost-students are extremely severe violations because of the awareness of the deviousness of the act, the underlying motivations for these types of violations often reflect the same causes as other forms of academic integrity violations [4].

Students have cited a variety of motivations for engaging in academic integrity violations. There are often personal reasons for cheating, including that students do not have time to complete the assignment, that they are overwhelmed by internal and external pressures to succeed [4], that they have low self-esteem [6] or lack of self-control [7], or that the motivation to "get ahead" exceeds any deterrent from cheating [8]. There are also systemic and organizational components that may make it more likely for students to cheat, such as that they have witnessed other students cheating and getting away with it [6], that many professors are not willing to spend class time talking about academic integrity because they believe that students should already know the rules [9], and that many elements are in place to depersonalize the college experience, from anonymous grading to large or online classes, so students feel less personally responsible for their behaviors [4]. 
Much of the literature on academic integrity has focused on cheating and punishments, rather than promotion of honesty and ethics in students. Thus, it could be more fruitful to focus on student motivations not to cheat and to capitalize on those factors, rather than approaching the topic from a perspective of catching and sanctioning students after it is too late. Students who have reported never committing academic integrity violations have cited reasons such as the influence of the professor and one's overall disapproval of cheating behaviors [8]. One's attitude towards academic integrity has been found to relate strongly to future academic integrity-related behaviors [7]; therefore, it is crucial for professors and institutions to openly create a culture of academic honesty. Furthermore, students who do not cheat do not value the idea of "getting ahead" [8], which suggests that perhaps there is more motivation to learn and engage with course material for the sake of mastery as opposed to an extrinsic reward, such as a grade. This finding would underscore the obligation of professors to create assessments that are connected to important learning objectives and transparency with students in explaining the benefits of completing such assignments.

Faculty perceptions of why students cheat can vary just as widely as students' reported motivations for cheating. A recent survey of faculty members indicated that some faculty believed students cheated because they only cared about their grades and were willing to cut any corners in order to achieve their goals, while other faculty members suggested that students did not know how to approach assignments correctly and were unaware of what was actually meant by academic integrity. The perceived motivations for cheating can greatly affect the ways that faculty approach this complex issue, from designing assessments to prevent cheating behaviors to dealing with students after they have potentially committed an academic integrity violation.

Academic integrity violations in high school are a big predictor of similar violations in college [10], and students who cheat once in college are likely to continue to cheat multiple times [4]. Thus, it is crucial for individual professors and also departments and universities to focus on best practices for educating students on ethical behaviors and how to ensure they are followed. Furthermore, if the educational process can tap into the professional ethics that students will eventually follow as professional engineers, students are more likely to internalize the appropriate ethical behaviors instead of just trying to avoid punishment during college [4].

It is an obligation of educators to create meaningful assessments of students, not only to benefit the students' overall learning but also to deter academic integrity violations. Students who reported cheating on college examinations stated that they did not feel guilty for their actions if the exam questions were not clearly tied to the students' future educational and career goals [11]. This paper will address best pedagogical practices that can be used to prevent academic integrity violations, from the use of meaningful and clear low-stakes assignments to the use of technology to detect when cheating has potentially occurred. When these recommendations are used consistently across the discipline, students will have a clear understanding of appropriate ethical behaviors and future engineers will be better prepared to work competently and ethically in the field. 


\section{Fantastic cheats - modern technology-driven cheating}

A wide body of research studies indicate that cheating is on the rise in higher education [12] [14]. Business and engineering students have been reported as some of the most likely to engage in cheating [15], [16]. The incidence of students using unauthorized online resources to cheat has been rapidly increasing [17] - [19]. With the availability of online tutoring services like Chegg, smartphone devices, online companies who provide paid services for assistance with school work and take online classes on the student's behalf, students have access to a new set of very convenient resources and tools to cheat.

Chegg is an online tutoring service (website and mobile app) offered by the parent company Chegg Inc. which is an American educational technology company. A Chegg study subscription includes access to solution manuals of over 9,000 textbooks (as advertised on their webpage) and access to 'Expert tutors'. Students can post a photo of the question and the service claims that an expert tutor will answer the question in as little as 30 minutes. The subscription costs are around \$14.99 a month to access these services. In July 2019, the company reported to have 2.23 million subscribers, a 30\% increase over one year, and a net revenue of $\$ 93.9$ million. The resources offered by the company are marketed to aid the student in studying, but on the contrary, these can also be very easily misused by the students.

Students have found unique and novel ways of misusing these online resources and technology. With the Chegg mobile app it takes just a few seconds to post a picture of a question for a tutor to answer. Students post the exam questions during the exam which the tutors answer in a short period of time (Figure 1). On searching the Chegg database for questions it is very easy to find a large amount of exam questions which have been answered by the tutors. The tutors are paid based on the questions answered so it is common to find multiple tutors answering in a short period of time. Students are usually restricted from carrying their smart phone devices in the exam halls. In smaller classes, this is easier to monitor, but as enrollment and class sizes grow, it becomes increasingly difficult to monitor this behavior. Students often share the login information for Chegg with each other. As a result, it is difficult to find the person uploading the question, even if the account information of the person posting the question is obtained from the service provider. Students often work in groups and use self-destructing private messaging apps to communicate; if one person in the group gets a chance to look up the solution on Chegg, they text the solution to the rest of the students. Studies indicate that the prevalence of the use of online sources of the solution manuals to textbooks and problem solving services to cheat on homework is increasing [12], [20], [21]. Furthermore, the process of finding the solution to numerical problems has become increasingly simplified with the databases of the online services like Chegg. Entering the first few words of a numerical in the google search engine brings up the results of the solutions posted on the online services (Figure 2). Coursehero is another online service that is popular with students; it provides access to solution manuals, old tests, homework problems, and class notes. There are many other sites that provide similar services, including studybible.com, koofers.com, and slader.com. Even though these services are positioned as a learning resource, one of the big issues with them is that if the student wants to cheat, these websites offer all the tools they need to do so. 
There are many companies that offer paid services to take online classes on the student's behalf. They offer a wide variety of services like writing essays or papers, completing homework assignments, lab reports, case studies, quizzes, exams, etc., while few offer to take the entire course on the student's behalf. Some of the popular websites offering these services are onlineclassdoer.com, nerdifyit.com, acemyonlineclasses.com, onlineclasstutorsforyou.com, takemyonlineclassnow.com takeyourclass.com, speedypaper.com, paperhelp.org, essaypro.com, superbpaper.com, and homeworkfor.me. The student can place an order on the website by providing all the details of the task involved and the deadlines. The company then assigns a tutor or an expert having the appropriate academic background to work on the task. These companies market the services they provide as academic consulting; they claim to provide their customers with only examples of written work and solutions to the tests for assistance purposes. How the student uses this is not their business.

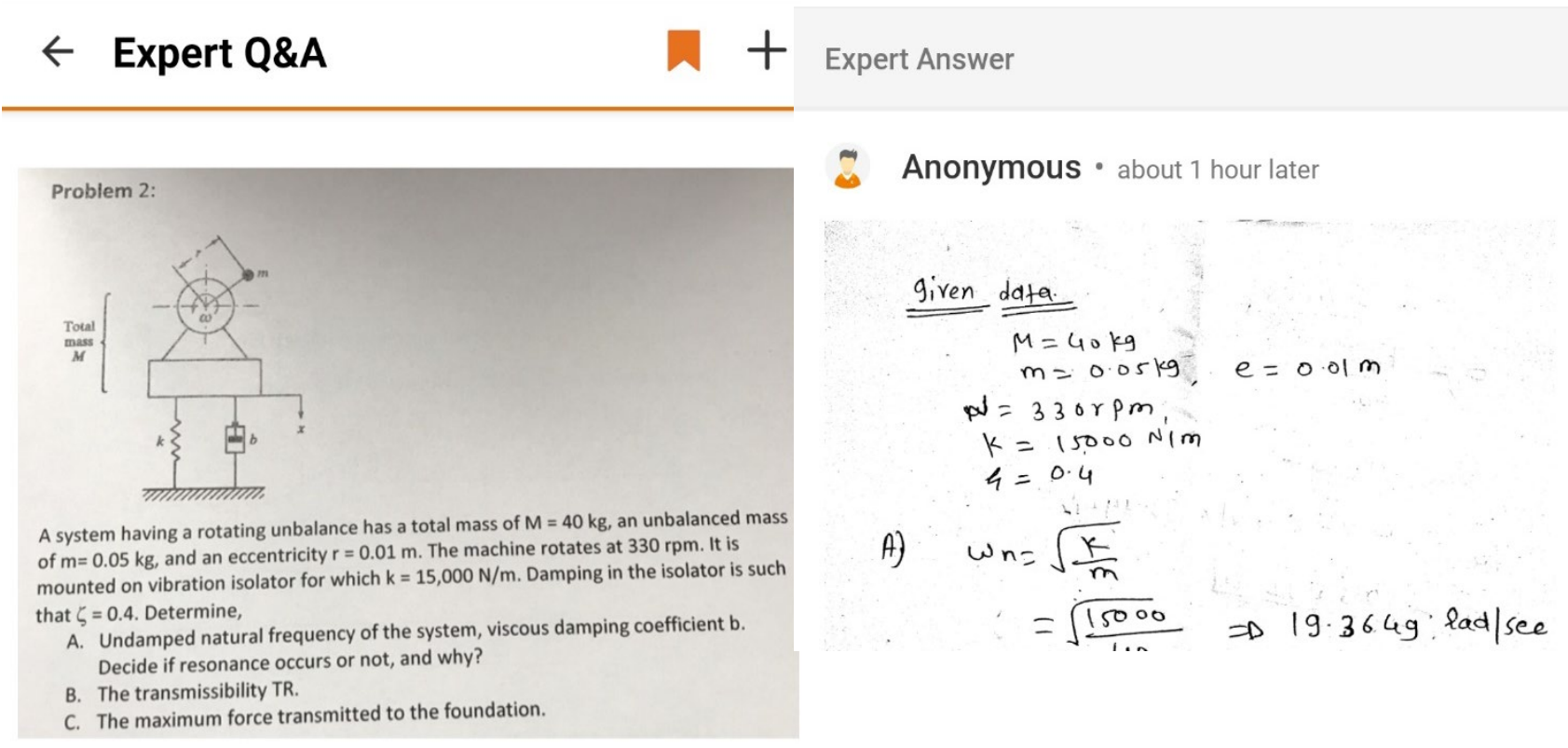

Figure 1: Screen grab of a question from a final exam posted on the Chegg mobile app, and the solution posted by an expert within an hour 


Q All 国 News $\odot$ Shopping $\bullet$ Images $\square$ Videos $\vdots$ More Settings Tools

About $132,000,000$ results $(0.60$ seconds)

www.chegg.com , homework-help , air-20-c-1-atm-flows-past-flat-pl... $\mathbf{v}$

Solved: Air at $20^{\circ} \mathrm{C}$ and 1 atm flows past the flat plate in Fig ...

Air at $20^{\circ} \mathrm{C}$ and $1 \mathrm{~atm}$ flows past the flat plate in Fig. P7.24 under laminar conditions. There are two equally spaced pitot stagnation tubes, each placed $2 \mathrm{~mm}$...

www.chegg.com , ... , mechanical engineering questions and answers $\mathbf{v}$

Solved: Air At 20 Degree C And 1 Atm Flows Past The Flat P ...

Question: Air At 20 Degree C And 1 Atm Flows Past The Flat Plate As Shown In Figure Below Under Laminar Conditions. There Are Two Equally Spaced Pitot ...

Figure 2: The process to find solutions to numerical problems has become very simplified, upon entering the first few words of the numerical in a search engine, solutions for the numerical from the online problem solving services conveniently pop up

\section{Fantastic cheats - what to do when you find them?}

It is very important to maintain consistency and a standard approach in dealing with academic integrity violation reports. Most universities have an office of community standards to deal with such cases. The community standards office is usually part of or is closely affiliated with the Dean of Students office. The role of an effective community standards office is to uphold the honor code (also known as the code of student conduct) as well as to ensure due process to all those who are accused. Figure 3 outlines the most commonly used procedures to deal with academic integrity violation incidents. 


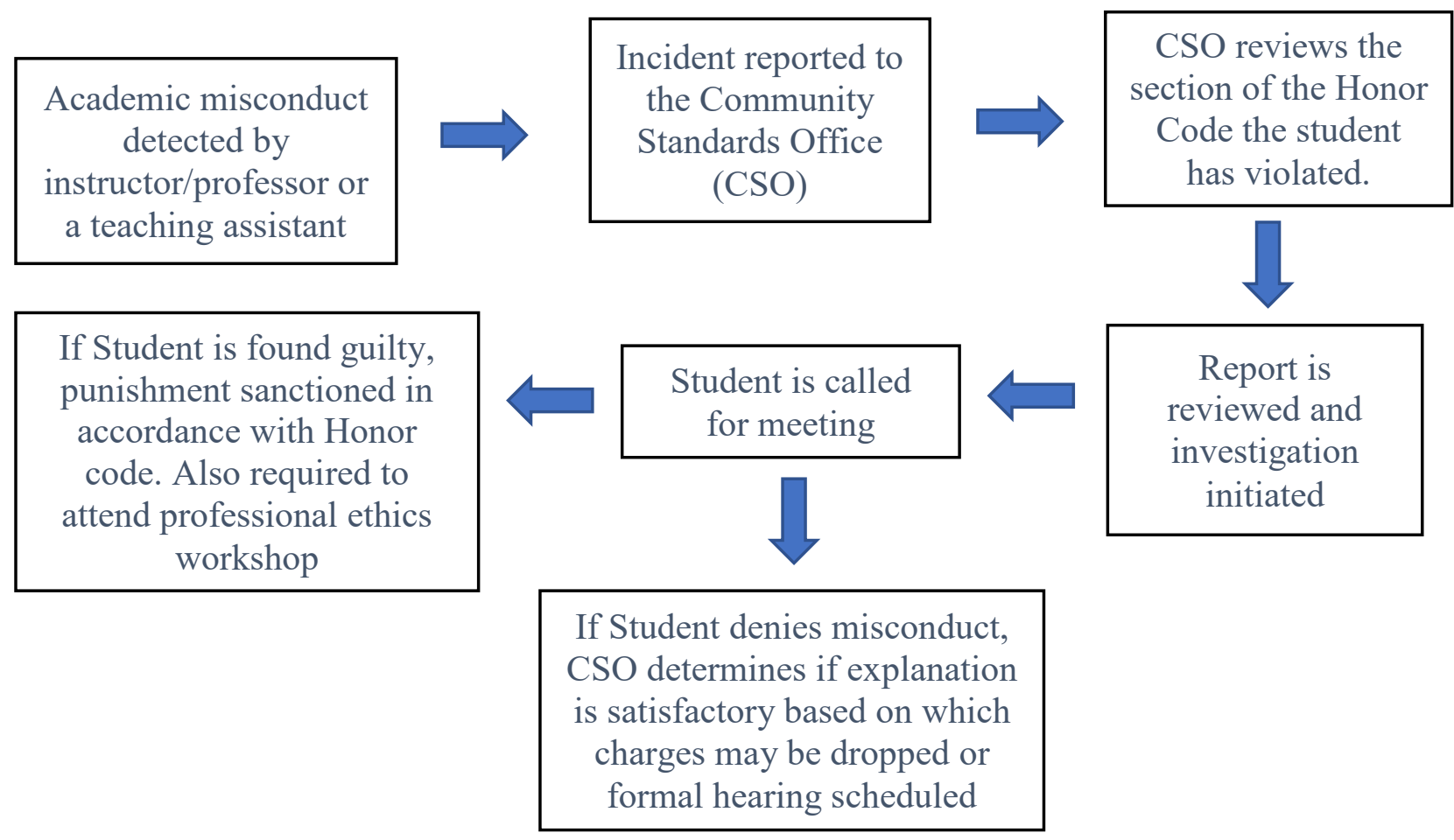

Figure 3: A typical flow for handling academic integrity violation incidents

In addition, there are many things that can be done to minimize the occurrences of academic integrity violations. Presented below are some of the best practices that should be implemented at all institutions of higher education.

1. All suspected or confirmed cases of academic dishonesty or misconduct must be reported to the Community Standards Office (or the Office of the Dean of Students, as appropriate). Teaching Assistants and Proctors should report the incidents to the primary instructor for the course. This step is crucial that even if an instructor wants to handle the investigation themselves, a record must be maintained at the University-level of any student who has violated the academic integrity policies of the university.

2. Such reporting requirements should be clearly stated in all relevant policy documents, e.g., Academic Integrity Policy, Faculty Handbook, etc.

3. Periodic departmental and institutional faculty meetings should include sessions on educating instructional staff on updated policies and procedures as well as best practices to minimize cheating. Use of modern technology tools can be a very effective resource.

4. Use of teaching workshops and open forums should be made to address academic integrity issues.

5. Academic integrity policies and procedures should be a mandatory part of the onboarding process for all new hires.

6. Students should learn about the importance of the honor code and the seriousness of sanctions if they are found in violation of it. College 101 and other first-semester courses as well as new student orientation programs are ideal platforms to reach new students. All the relevant policy documents including information on student rights should be readily 
available on the university website and should be referred to in course syllabi and course description pages.

7. Doctoral and Graduate students in particular, and all students engaged in research activities in general should be made aware of the serious consequences of falsifying and/or fabricating data, reports, processes, and research results. It should be made clear that there is no excuse for plagiarism. Many institutions even state in their policy that they reserve the right to rescind the degree for academic integrity violation cases discovered and proved after graduation.

\section{Fantastic cheats - how to tackle them?}

This section will present some of the best practices, strategies, and tips to minimize cheating in the classroom [22],[23]. It is organized in the following broad categories-

\section{General classroom practices}

- Define policies explicitly in the syllabus. Students should be clear on your policies regarding academic dishonesty, attendance, late submission of homework and assignments, use of electronic devices in class, exams and assessments, and consequences of violating these policies. A few sample policies are shown in figure 4 below. Please note that these policies should be used just as a guideline. Each instructor should adapt to his/her particular course.

- Convey to your students that you have a zero tolerance policy and take strict action against academic dishonesty cases. Be explicit about your grading policy. For example, if you intend to give a zero for an assignment when there is an academic integrity violation, say so. If you intend to report the student to the CSO, state that explicitly.

- Let your students know, to the extent possible, of previous academic dishonesty cases caught in your class and the consequences bore by the students.

- Establish relevance of each homework assignment, paper, project, presentation, lab and the overall course to students' interests and career aspirations.

- Speak with students about the relationship between academic integrity and their future chosen career and the implications of academic dishonesty.

- Do your best to create a climate of integrity by stressing the importance of honest work, pointing out that it is in the best interest of all students to maintain the reputation of their degree. Tolerating cheating by doing it, or not reporting it when it is observed, puts in jeopardy the integrity of everyone's academic accomplishments.

- Be wary for how students cheat. Once a method of cheating is identified, create a solution that does not allow this type of cheating in the future. 


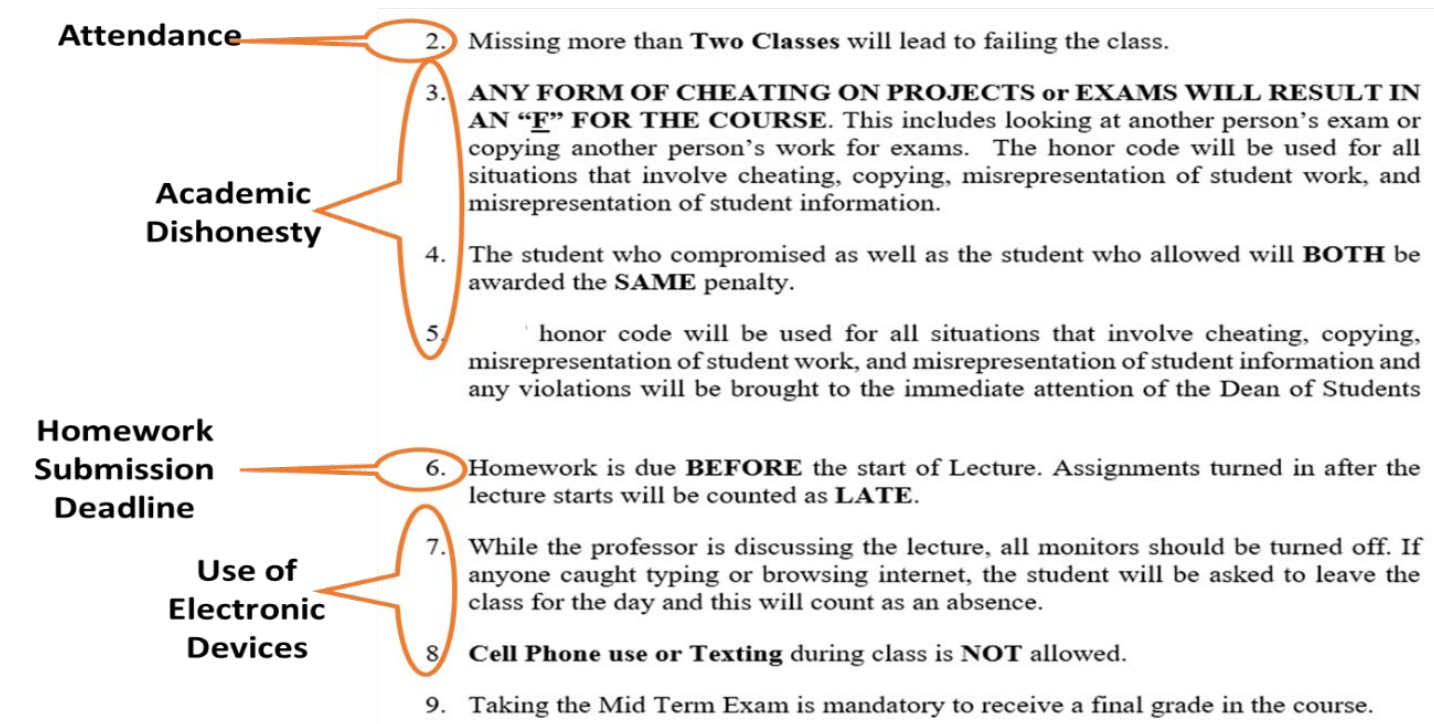

Figure 4: A sample of academic policies that can be added to course syllabi

\section{Cheating during exams}

Cheating on exams can be either opportunistic or planned. Here are a few tips to prevent cheating during exams-

- Questions asked on the exams should never be repeated from previous semesters. In this technologically advanced era, do not ever recycle your exams.

- Questions from textbooks and publisher text banks should be altered to avoid students copying from a solution manual that is readily available online.

- If possible, at least two different sets of exams should be created with different (but equivalent) questions for adjacent examinees. If the same questions are being used, at least the order of the questions should be varied. Various programs are available to easily shuffle the order of questions to create multiple versions of the exam.

- Be reasonable. Evaluate and test students on what you have taught. Do not make your exams too hard or too long.

- Avoid multiple choice questions on an exam. Yes, they are easy to grade, but easy to cheat on as well.

- Request additional proctors from your department if possible or request your teaching assistants to help. Provide clear instructions to teaching assistants and proctors for proctoring exams.

- Practice active proctoring. Walk around the class in random patterns. Proctors should not be focused on anything other than proctoring. Multiple proctors should be present for large classes.

- The instructors and/or proctors should reach the exam center before time to ensure that there is enough space between students to prevent opportunistic cheating. Request bigger classrooms for major exams, if possible. 
- Before entering an exam room, have students deposit, at a designated area, all backpacks, caps, gloves, coats, notebooks, books, and technology of any kind (laptops, ALL cell phones, tablets, graphing calculators and programmable watches) unless necessary for taking the exam. Students should receive advance notice of this policy in case they would rather lock up their belongings in a locker or leave valuable items at home.

- Calculator use must be monitored closely and only permissible models should be allowed. Do not allow students to use their smartphones as a substitute for a calculator. Instead, carry a few calculators with you to the exam.

- Cheat Sheets: Beware of allowing students to use their own cheat sheets, which may be prepped with answers in advance or can be passed around during the exam. Decide what you are really testing - do you want students to prove they have memorized the formula, or that they can use the formula to solve a problem? Consider using "open book" tests when you want to test a skill rather than content knowledge. It eliminates some reasons why students cheat. Finally, you can also create formula/cheat sheets and pass them out with the test.

- Monitor a student's need to use a restroom during an exam. Allow only one student at a time to leave the exam room.

- Include a statement on your exam regarding academic integrity, what the consequences are if there is violation of the code, and have students sign it.

- Consider using technology tools such Respondus lockdown browser and ProctorU for conducting exams on a computer (for both online as well as face-to-face courses).

\section{Plagiarism}

Plagiarism is the act of wrongfully taking someone else's work or ideas and passing it as your own or using it without crediting the source. Here are some tips to reduce plagiarism in our classrooms -

- Use turnitin.com or similar software to check for plagiarism in writing assignments.

- Be wary of sudden improvements in written ability or style of students.

- Run the program/source code submitted by students for programming assignments.

- Be aware of sites such as Chegg.com, Essayshark.com, and Github.com. Students are less likely to use these resources if they know that their instructor knows about them.

- For mathematics-based or engineering courses, have the assignment be different for every student by using formula-based questions on learning management systems or publisher websites (such as Mymathlab and Wileyplus) that generate problems with different numbers for each student.

- Plagiarism Quiz - Teach students about plagiarism and academic integrity violations like you would teach any other course material. Give students a quiz to ensure that they truly understand what is meant by plagiarism and give them opportunities to practice writing or citing materials appropriately.

- Multiple low stakes assignments - Students have been found to cheat more when their grade is dependent upon one major assignment [24]. Whenever possible, large assignments should be broken down into smaller sections, so that students do not feel the overwhelming burden 
of one assignment determining their final grade and also to ensure that students do not run out of time to complete an assignment and then feel forced to plagiarize.

- Transparent assignments - Finally, students report cheating more often when they do not understand what is being required of them in an assignment [10]. Instructors should clearly articulate the purpose of assignments required in the class, the ways in which those assignments will connect to the students' educational and career aspirations, the expectations of the assignment, a grading rubric, and perhaps samples of successful past assignments [25]. When students feel prepared to complete the course requirements, they will have more confidence to do that work themselves.

\section{Conclusion}

Academic integrity violations that go without detection or consequence have the potential to tarnish the value of the degree for all students from an institution. When these problems proliferate, companies are unable to decipher who is the most prepared or qualified candidate applying for a position upon graduation. The success within the field of engineering is reliant upon ethical and competent professionals, and much of this preparation begins within the realm of promoting academic integrity behaviors. All institutions of higher education put high value on academic integrity. However, the success rate has become very low for age-old common sense based practices to counter academic integrity violations. Instructors may feel threatened or overwhelmed with the access that students have today to online resources and technologically sophisticated means of cheating; however, with thoughtful pedagogy, incorporation of academic integrity policies within one's courses, and assignments that are designed to focus on students incrementally developing their skills rather than large-stakes assessments, instructors and institutions have the power to prevent dishonest behaviors among their students. 


\section{References}

[1] T. L. Giluk and B. E. Postlethwaite, "Big five personality and academic dishonesty: a metaanalytic review," Personality and Individual Differences, vol. 72, pp.59-67, Aug. 2014.

[2] L. W. Thompson, J. H. Bagby, T. N. Sulak, J. Sheets, and T. M. Trepinski, "The cultural elements of academic honesty," Journal of International Studies, vol. 7, no. 1, p.136+, Jan./Feb. 2017.

[3] J. Payan, J. Reardon, and D. E. McCorkle, "The effect of culture on the academic honesty of marketing and business students," Journal of Marketing Education, vol. 32, no. 3, pp.275-291, Aug. 2010.

[4] M. Walker and C. Townley, "Contract Cheating: A new challenge for academic honesty?" Journal of Academic Ethics, vol. 10, pp. 27-44, Feb. 2012.

[5] L. P. Hollis, "Ghost-students and the new wave of online cheating for community college students," New Directions for Community Colleges, vol. 2018, no. 183, pp.25-34, Aug. 2018.

[6] A. van Zyl and A. Thomas, "Academic Honesty: perceptions of millennial university students and the role of moderating variables," KOERS-Bulletin for Christian Scholarship, vol. 80, no. 1, pp.1-15, Sept. 2015.

[7] H. Yu, P. L. Glanzer, B. R. Johnson, R. Siriam, and B. Moore, "Why College Students Cheat: A conceptual model of five factors," in The Review of Higher Education, vol. 41, no. 4, p.549+, Summer 2018.

[8] M. G. Simkin and A. McLeod, "Why do college students cheat?," Journal of Business Ethics, vol. 94, no. 3, pp.441-453, July 2010.

[9] M. Peters, T. Boies, and S. Morin, "Teaching academic integrity in quebec universities: roles professors adopt," Frontiers in Education, vol. 4, no. 99, pp. 1-13, Sept. 2019.

[10] T. VanDeGrift, H. Dillon, and L. Camp, "Changing the engineering student culture with respect to academic integrity and ethics," Science and Engineering Ethics, vol. 23, pp.1159-1182, Nov. 2016.

[11] S. E. Küçüktepe, “College students' cheating behaviors," Social Behavior and Personality, vol. 45, no. 1, pp.101-111, Mar. 2014.

[12] Macfarlane, B., J. Zhang, and A. Pun, Academic Integrity: A Review of the Literature. Studies in Higher Education - STUD HIGH EDUC, 2012. 39: p. 1-20.

[13] Bernard E Whitley, J.P.K.-S., Academic dishonesty: An educator's guide. . 2002, Mahwah, NJ Erlbaum.

[14] Scott, R.H., Imperative Issues and Elusive Solutions in Academic Integrity: A Case Study. ASEE Conferences: New Orleans, Louisiana.

[15] Harding, T., et al., The theory of planned behavior as a model of academic dishonesty in humanities and engineering undergraduates. Ethics and Behavior 17 (3 or 4), 2007. 17.

[16] Shiyu, L., et al., Faculty Perspectives About Incorporating Academic Integrity into Engineering Courses. ASEE Conferences: Seattle, Washington.

[17] Ryan, T., et al. A Longitudinal Study of the Perception of Academic Integrity among Students and Faculty. in ASEE Annual Conference \& Exposition, Columbus, Ohio. https://peer. asee. org/27473.

[18] Moyer, B.E., R.D. Kelley, and R.A. Youchak, Understanding and influencing student attitudes toward ethical classroom actions. ASEE Annual Conference and Exposition, Conference Proceedings, 2015. 122. 
[19] Samson Pepe, G., et al., Interim Results of a Longitudinal, Multi-site Survey of Perceptions of Academic Integrity. ASEE Conferences: Salt Lake City, Utah.

[20] Adam, T.M. and G.B. Lisa, Ten Years in the Trenches: an Updated Suite of Scenario-based Academic Integrity Videos. ASEE Conferences: Salt Lake City, Utah.

[21] Carpenter, D.D., et al., Engineering Students' Perceptions of and Attitudes Towards Cheating. Journal of Engineering Education, 2006. 95(3): p. 181-194.

[22] "Best Practices Related to Academic Integrity PDF". Accessed on Apr. 27, 2020. [Online]. Available:https://www5.njit.edu/provost/sites/provost/files/lcms/docs/Best_Practices_relate d_to_Academic_Integrity.pdf

[23] "Best Practices Related to Academic Integrity". Accessed on Apr. 27, 2020. [Online].

Available: https://www5.njit.edu/undergradstudies/best-practices/

[24] H. J. Passow, M. J. Mayhew, C. J. Finelli, T. S. Harding, and D. D. Carpenter, "Factors influencing engineering students' decisions to cheat by type of assessment," Research in Higher Education, vol. 47, no. 6, pp. 643-684, Sep. 2006.

[25] N. B. Milman, "Tips for success: The online instructor's (short) guide to making assignment descriptions more transparent," Distance Learning, vol. 15, no. 4, pp. 65-67, 2018. 